\title{
Harmonia entre a prática pedagógica de professores de ciências e a música popular brasileira: possibilidades para um ensino CTS
}

\section{Greiciele da Silva Dias iegrs@yahoo.com.br \\ 0000-0002-8685-102X \\ Secretaria Municipal de Educação, Duque} de Caxias, Rio de Janeiro, Brasil.

\section{Jorge Cardoso Messeder jorge.messeder@ifri.edu.br} 0000-0002-7396-1596 Rio de Janeiro, Nilópolis, Rio de Janeiro, Brasil.

\begin{abstract}
RESUMO
A investigação da qual originou este artigo teve como objeto de estudo as possibilidades que oficinas de música com temas sociocientíficos podem trazer para alfabetização científica. O estudo qualitativo foi realizado com alunos do quarto ano do Ensino Fundamental. A pesquisa se alicerçou na literatura disponível ao Ensino de Ciências nos anos iniciais e estímulo ao desenvolvimento da alfabetização cientifica. Os temas sociocientíficos foram elencados considerando as propostas curriculares oficiais e a contextualização com a realidade da escola onde as oficinas foram aplicadas, sendo eles: lixo e meio ambiente. Para dinamizar as discussões, foi utilizada a música "Lixo no Lixo" do grupo Falamansa. A partir da interpretação da letra da canção, foram relacionados conceitos científicos e tecnológicos a situações vividas pelos alunos. A oficina de música para o Ensino de Ciências possibilitou uma prática docente mais dinâmica e desenvolveu nos discentes capacidades argumentativas, contribuindo para o aprimoramento da cidadania.
\end{abstract}

PALAVRAS-CHAVE: Ensino de ciências. Alfabetização científica. Temas sociocientíficos. Ensino fundamental. Oficinas de música. 


\section{INTRODUÇÃO}

O Ensino Fundamental é a etapa inicial da educação e tem por objetivo a formação básica do aluno, desenvolvendo conhecimentos do mundo em que vive e dos valores que a sociedade está fundamentada, assegurando a formação para o exercício da cidadania (BRASIL, 1996).

A abordagem Ciência-Tecnologia-Sociedade (CTS) no ensino fundamental é importante aos alunos para aproximá-los às primeiras concepções acerca do conhecimento científico e tecnológico sistematizados pelo ser humano, engendrando sua compreensão dos avanços e retrocessos causados, assim como os impactos na sociedade, o que estimulará a noção crítica e sua participação cidadã no mundo (FAGUNDES; PINHEIRO, 2013, p.22).

Considerando que é um desafio aos professores desenvolverem atividades que apresentem a ciência e a tecnologia como elementos marcantes no cotidiano, é necessária a busca por estratégias de ensino que contribuam para o questionamento, formulação de hipóteses e atuação na sociedade.

Diante deste cenário, a música se constitui como uma alternativa lúdica possível para dinamizar o ensino e superar a defasagem conceitual, pois contribui para os alunos reconhecerem a ciência como um tema presente em seu cotidiano, incentivando a reflexão, a sensibilidade, a construção de valores, dentre outros aspectos (OLIVEIRA et al., 2008, p.3).

A relevância desta pesquisa parte da necessidade dos docentes das séries iniciais encontrarem estratégias para o ensino de ciências que estimulem a problematização e o debate, e busquem a reflexão, priorizando a utilização da música para a abordagem de conceitos sociocientíficos que estimulem à alfabetização científica dos alunos.

Nesse contexto, a presente pesquisa tem por finalidade discutir a contribuição que as letras das canções podem trazer a alfabetização científica dos alunos do primeiro segmento do Ensino Fundamental, por meio de uma oficina de música.

O desenvolvimento de oficinas de música pode garantir aos alunos a oportunidade de exercitarem o senso crítico e a participação, como meios para a conquista da cidadania, são caminhos para desenvolver o pensamento críticocoletivo e se opor à educação tradicional que privilegia a memorização de conteúdos.

\section{Fundamentação Teórica}

As pesquisas em Ensino de Ciências nas últimas décadas apontam que os currículos nesta área de conhecimento estiveram vinculados aos processos históricos e sociais, relacionados aos diferentes interesses conforme a época (SOARES et al., 2007, p.5). O modelo tradicional de educação, que perdurou durante anos e que ainda encontramos vestígios, trazia uma concepção 
conservadora da sociedade, a escola tinha como papel transmitir conteúdos e ao aluno cabia à reprodução e memorização, a ciência era tida como conhecimento inquestionável, absoluto.

A aplicação do método científico, baseado na razão instrumental, na observação cuidadosa de fenômenos e na neutralidade do pesquisador, estimulava a ciência como produção essencial de conhecimentos objetivos acerca das realidades naturais e sociais. De acordo com essa concepção clássica, a contribuição que a ciência trazia poderia assistir somente ao bem-estar dos sujeitos, deixando de lado as questões sociais para buscar exclusivamente as verdades científicas (NASCIMENTO et al., 2010, p. 230).

Diante dos novos desafios da sociedade contemporânea se almeja outra visão de conhecimento, onde a escola deve transmitir o conhecimento priorizando a problematização e a contextualização, os alunos devem ser partícipes na construção de seu conhecimento, o professor o responsável por mediar situações dialógicas, em uma relação horizontal, e a ciência é vista de forma crítica (FREIRE, 2011).

Discutir os avanços da ciência e tecnologia com os alunos, suas causas e consequências, contemplando dimensões sociais, econômica e políticas e contextualizando a concepção da ciência como fruto da criação humana, originou o movimento Ciência, Tecnologia e Sociedade (CTS) no qual o processo ensinoaprendizagem passa a ser compreendido "como a possibilidade de despertar no aluno a curiosidade, o espírito investigador, questionado e transformador da sociedade" (PINHEIRO et al., 2007, p. 77).

Para Pinheiro et al. (2007) é necessário à população ter acesso e compreensão das informações sobre o desenvolvimento tecnológico e também condições de avaliar e participar das decisões que possam atingir a sociedade em que vive.

As pessoas precisam ter acesso á ciência e à tecnologia, não somente no sentido de entender e utilizar os artefatos e mentefatos como produtos ou conhecimento, mas também, opinar sobre o uso desses produtos, percebendo que não são neutros, nem definitivos, tampouco absolutos (PINHEIRO et al., 2007, p.1).

A implementação da Lei de Diretrizes e Bases da Educação Nacional (LDB) traz a educação em princípios de liberdade e solidariedade humana, sendo dever da família e do Estado, e tem por finalidade o pleno desenvolvimento do educando, seu preparo para o exercício da cidadania e sua qualificação para o trabalho (BRASIL, 1996).

A necessidade de reorientação nas práticas de ensino descontextualizadas é evidenciada nesta lei, definindo uma educação escolar voltada para a formação de alunos que tenham participação ativa na sociedade. O conhecimento científico é importante para que os alunos possam ter compreensão da natureza, da tecnologia e da sociedade, e assim possam construir valores e participar democraticamente na sociedade, atuando de forma consciente. (BRASIL, 1996).

Os Parâmetros Curriculares Nacionais (PCN) para o Ensino Fundamental são referenciais que auxiliam a construção do trabalho docente interdisciplinar, com o intuito de ser um instrumento de apoio às discussões pedagógicas. Os PCN foram norteados pelo MEC para propor mudanças curriculares e metodológicas nas práticas escolares, porém foram pouco discutidos nas escolas e por consequência é pouco compreendido pelo professor (RICARDO; ZYLBERSTJN, 2007, p. 340).

Apesar dos atuais documentos educacionais nortearem o Ensino de Ciências em que se privilegie a criticidade e a investigação, a disciplina ainda tem sido 
ministrada de forma descontextualizada, priorizando a memorização em exercícios e atividades que não contextualizam os conceitos científicos trabalhados (SANTOS, 2007).

Os motivos são destacados por Viecheneski et al. (2011, p. 855) quando afirmam que os profissionais se sentem pouco seguros e qualificados para ensinar ciências, "em função de uma formação docente precária quanto ao embasamento conceitual para o trabalho com ciências; entre outras".

O Ensino de Ciências por meio de temas sociocientíficos contribui para que uma prática pedagógica ultrapasse o ensino memorístico e disciplinar, pois propicia aos alunos relacionarem conhecimento cientifico com situações de vida e aplicarem os conceitos a preendidos em seu contexto social (MUNDIM; SANTOS, 2012, p. 790). O desenvolvimento de temas sociais que estejam presentes na vida dos alunos tornará a aprendizagem mais significativa.

A escola nas séries iniciais deve trabalhar com noções científicas para que os alunos compreendam o mundo que o cerca, para mais tardiamente aprofundar esses conceitos. A intenção é que a curiosidade inerente às crianças seja trabalhada de forma a dar significados e sentidos a conceitos que serão aprofundados na próxima etapa.

De acordo com Viecheneski et al. (2012, p. 860) a alfabetização científica tem como finalidade preparar os alunos para a vida em sociedade, levando em conta sua atuação cidadã, crítica e responsável. Assim, são necessárias ações educativas para a promoção da alfabetização científica no contexto escolar, pois "implica em discutir e desvelar a ciência, a tecnologia e a sociedade, abordando as interrelações entre essas e os aspectos históricos, sociais, econômicos e culturais".

Parte-se da concepção que a alfabetização científica é um importante processo que permitirá aos alunos a compreensão dos assuntos que abordam a ciência e a tecnologia, indo além de mera reprodução de conceitos científicos, sem envolvimento com o mundo (DELIZOICOV; LORENZETTI, 2001, p. 40). Logo, compreender cientificamente o mundo a sua volta, participar ativamente, estar ciente das decisões a serem tomadas, é estar alfabetizados cientificamente.

A utilização da música pode contribuir para motivar os alunos no envolvimento com as temáticas sociocientíficas, pois por fazer parte do cotidiano aproxima o aluno despertando interesse, desenvolvendo a aprendizagem e permitindo uma formação mais reflexiva e crítica.

As canções carregam cultura, história, retratos, visões do homem perante a sociedade e sua análise "pode ser um interessante momento para um exercício interdisciplinar, ainda mais que a música carrega elementos motivadores com potencial para despertar o interesse por determinado tema ou acontecimento, particularmente entre os jovens." (MOREIRA; MASSARANI, 2006, p. 293).

O desafio para o professor é a promoção de atividades voltadas para o interesse do aluno, com estratégias de ensino que contribuam para sua aprendizagem, e as letras de canções podem ser um instrumento eficaz nesse processo.

Muitas pesquisas recentes têm sido realizadas em que a música aparece como recurso didático em sala de aula na educação básica para ensinar ciências, como, Barros et al. (2013, 2015), Benetti et al. (2014), Silva e Oliveira (2008), Silveira e Kiouranis (2008), Moreira e Massarani $(2006,2007)$, dentre outros.

Pode-se constatar ao longo da história humana que a música tem desempenhado um estímulo ao desenvolvimento humano, e que os documentos 
oficiais que legislam em favor de uma educação integral ressaltam sua importância para o crescimento do ser humano (LOUREIRO, 2010).

Benetti et al. (2014) ressaltam o papel da música na escola, colocando que:

[...] entre as diversas linguagens artísticas, a música tem um papel fundamental na escola, pois é um veículo facilitador da construção do conhecimento e da formação de um sujeito autônomo diante do mundo sonoro no qual vive capaz de fazer suas escolhas musicais, além de se tornar sensível aos estímulos que esta arte pode oferecer. (BENETTI et al., 2014, p. 482)

Esses autores nos trazem dados sobre a mudança de comportamento e nas relações interpessoais das crianças em sala de aula quando motivadas pela escuta da música, ressaltando que à medida que as crianças entram em contato com a música, principalmente de ritmos mais calmos, permanecem mais envolvidas no processo educativo e mais atenciosas, o mesmo não acontece com ritmos acelerados, pois a capacidade de dispersão é maior. A música pode ser utilizada como uma estratégia eficaz no ensino das disciplinas de Ciências, pois apesar de a música não ilustrar visualmente o conteúdo que pode ser explorado, passa a ser um veículo de expressão que é capaz de aproximar mais o aluno do tema a ser estudado (BARROS et al., 2013, p. 90).

A música ainda é pouco utilizada em sala de aula, ainda que possua potencialidade para o aprendizado de diversas áreas, inclusive ciências (MOREIRA; MASSARANI, 2007, p. 294). No Ensino Fundamental justifica-se pelo fato do professor sentir insegurança em realizar um trabalho musical, pois a música não foi contemplada na sua formação, já que a grande maioria possui apenas formação em nível médio, Magistério, ou curso de Pedagogia, apesar de reconhecerem a importância e validade da música na escola (SPANAVELLO; BELLOCHIO, 2005).

Nas letras de canções da música popular brasileira encontram-se visões e temas sobre a ciência, tecnologia e seus impactos na vida moderna que quando utilizada de maneira a explorar essas relações, pode conduzir interessantes questionamentos (MOREIRA; MASSARANI, 2007, p. 300).

Apresentando grande potencial para problematização, uma vez que pode abordar temas que estão presentes no cotidiano, a música pode ser utilizada como estratégia em contraposição a aula expositiva, estreitando o diálogo entre os alunos, professores, e conhecimento científico, aumentando a sensibilidade e criatividade (SILVEIRA; KIOURANIS, 2008, p. 29).

Silva e Oliveira (2008) afirmam que é bastante relevante trabalhar músicas com temas possíveis para discussão, para despertar a criticidade dos alunos, e constataram em sua pesquisa, em que os alunos interpretaram músicas com conceitos ecológicos, que o envolvimento dos alunos nestas atividades despertou o senso crítico em relação à problemática ambiental.

É fundamental que o docente esteja comprometido em formar seus alunos alfabetizados cientificamente e como recurso didático que auxilia na comunicação e reflexão entre os alunos à utilização da musica torna-se um instrumento valioso, para desenvolver a linguagem e interpretação dos alunos, contribuindo para a aprendizagem e criticidade (SILVA; OLIVEIRA, 2009).

\section{Procedimentos metodológicos}


O estudo desenvolvido no presente trabalho se baseou na abordagem qualitativa apoiada em observações e dados coletados ao longo do trabalho com os sujeitos envolvidos.

Seguindo a característica da natureza dessa pesquisa, Minayo (2012, p. 21) coloca que "trabalha com universo dos significados, dos motivos, das aspirações, das crenças, dos valores e atitudes", sendo compreendido como parte da realidade social, pois o ser humano é capaz de agir e interpretar suas ações.

Utilizou-se a pesquisa participante considerando a participação e o envolvimento dos sujeitos no desenvolvimento e na construção do conhecimento, já que dentre outros propósitos, esta metodologia "pretende ser instrumento pedagógico e dialógico de aprendizado partilhado; possui organicamente uma vocação educativa e, como tal, politicamente formadora" (BRANDÃO; BORGES, 2007, p.57).

O desenvolvimento da pesquisa ocorreu em uma escola municipalizada em Duque de Caxias (RJ), tendo como público alvo uma turma de quarto ano do primeiro segmento do Ensino Fundamental, onde seis oficinas de músicas foram aplicadas. Porém, para recorte adequável nesta investigação, destaca-se uma oficina, contemplando os resultados encontrados.

Primeiramente foram selecionados os temas sociocientíficos. Para isto foram considerados os estudos realizados nas propostas curriculares oficiais e a contextualização com a realidade da escola onde as oficinas foram aplicadas, sendo eles: Lixo e Ambiente,

Para o planejamento das oficinas, a música foi selecionada utilizando o site www.letrasdemusica.com.br. Este site disponibiliza cifras, letras e vídeos de diversas músicas. A canção escolhida foi "Lixo no Lixo" do grupo Falamansa.

A segunda etapa foi a aplicação da oficina, com duração de três horas, com questionamentos sobre a letra da canção e que priorizavam a discussão e reflexão do grupo, a interpretação da música e a relação com os conceitos sociocientíficos, onde foram obtidos registros de fotos, filmagens e gravação de voz dos alunos.

A perspectiva contínua de ação-reflexão permitiu a observação e a coleta de dados, em uma abordagem qualitativa, corroborada pela literatura especializada, confirmando, ou não, a validade dos aspectos propostos, o que propicia a validação de uma teoria (BORTONI-RICARDO, 2008).

\section{Discussões dos Resultados}

A oficina "Lixo e Ambiente" iniciou-se com a audição da música Lixo no Lixo, interpretada pelo grupo Falamansa. Nesse dia, 22 alunos estiveram em sala de aula, que foi arrumada com as cadeiras dispostas uma ao lado da outra, formando um círculo, para que o ambiente ficasse mais propício ao diálogo, onde todos os alunos pudessem se ver face a face. Os alunos receberam a letra da canção (Figura1) impressa para lerem e interpretarem a música. 
Figura 1 - Letra da música Lixo no Lixo.

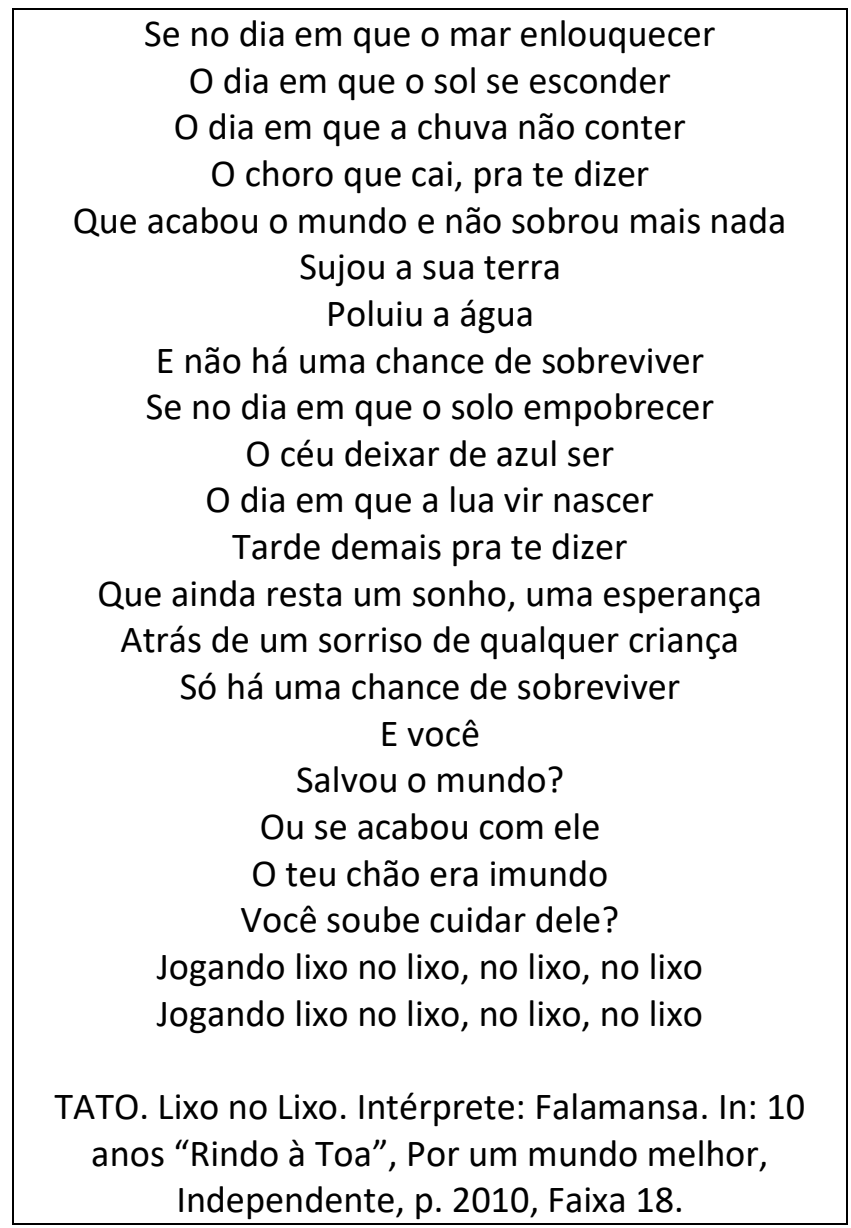

Fonte: autores.

O tema lixo e as implicações ao ambiente, considerando os aspectos sociais, ambientais, econômicos e políticos, foram colocados em discussão nesta oficina, questionando fatores vivenciados na comunidade onde os alunos residem, e ampliando para questões mais globais, relacionando à produção e ao consumo.

Os alunos foram atraídos pela canção e pediram para cantar o refrão. Em seguida, iniciamos o diálogo com questionamentos referentes à letra da música que retratava, de forma muito pertinente, o assunto desta oficina.

De acordo com a interpretação dos alunos a temática central da música se encontra no trecho:

"- E você? Salvou o mundo? Ou se acabou com ele? O teu chão era imundo? Você soube cuidar dele? Jogando lixo no lixo, no lixo, no lixo." (Aluno K).

Instigados à reflexão, os alunos responderam:

"- A música está falando que a gente tem que cuidar do lixo, jogar sempre na lixeira e quando tiver tudo sujo varrer (...)" (Aluna A).

"- E depois no caminhão do lixo. Porque são eles que levam a sujeira." (Aluno K). 
De acordo com a fala da aluna A é explícita a importância que o homem deve ter com o ambiente em que vive. Sobre isso Medeiros et al. (2011, p.1) coloca: "o ser humano deve passar a entender, desde cedo, que precisa cuidar, preservar e que o futuro depende do equilíbrio entre homem e natureza e do uso racional dos recursos naturais."

Por outro lado, o aluno $\mathrm{K}$ lembrou que existe a necessidade do lixo ser transportado pelo veículo adequado: o caminhão de lixo, pois não basta que o indivíduo cuide, é necessário que haja o transporte correto dos resíduos. Logo, é necessário que a prefeitura se comprometa com a coleta regular de lixo.

Diante do questionamento sobre a quantidade de lixo produzida pelas pessoas diariamente, a aluna respondeu:

"- As pessoas comem e jogam comidas fora. Usam papel higiênico, garrafa pet, tampinhas, latinha de cerveja, vários objetos que joga fora ao invés de reciclar e fazer outros objetos." (Aluna A).

De acordo com a fala da aluna, é possível verificar que reconhece a importância da coleta seletiva. Porém, alguns conhecimentos precisam ser reformulados, como o processo de separação de lixo orgânico e inorgânico, e o processo de tratamento de materiais do lixo, pois nem todo material é reciclável, como o papel higiênico citado em sua fala.

Compreendendo que o professor pode contribuir para reformulação do senso comum para o científico, e que é necessário despertar nos alunos as habilidades de análise, comparação, elaboração, hipótese e crítica, a professora chamou a atenção do grupo com a pergunta: “- Todo tipo de lixo é reciclado?". Desse jeito a turma obteve a tarefa de pensar e identificar coletivamente quais eram os materiais que podiam ser reciclados ou não. Sobre isso, Fabri e Silveira (2013, p. 80) colaboram dizendo que é através do ensino provocativo que os educandos começam a pensar e refletir sobre o conhecimento.

Ao realizar a análise dos versos "Se no dia em que o solo empobrecer. O céu deixar de azul ser", uma aluna interpretou fazendo inferências às condições climatológicas, dizendo que o céu ficava escuro quando ia chover, mas o aluno L fez uma análise que correspondeu melhor o sentido da música, interpretando que "quando coloca fogo em carro ou pneu o céu vai ficando preto".

Como a intenção nessa estrofe era discutir a poluição atmosférica causada pela queima de combustíveis fósseis, a colocação do aluno foi pertinente para debatermos sobre a temática, pois a poluição é uma questão global que atinge a dinâmica do planeta em seu equilíbrio (BRASIL 1997).

Para se referir à poluição do solo fazendo menção ao verso da música "Sujou a sua terra, poluiu a água. E não há uma chance de sobreviver" a aluna $\mathrm{A}$ exemplificou:

"- Quando a gente compra uma lata de sardinha, a gente pega só a sardinha e joga a lata fora, e aí o caldo da sardinha vai pra dentro da areia, e polui a terra e a água também." (Aluna A).

Ao analisarmos a colocação da aluna, percebemos que fez menção ao líquido que escorre do lixo denominado chorume, que polui o ambiente e o deixa malcheiroso. A resposta demonstra fragilidade na construção desse conceito científico, logo, a classe foi direcionada à compreensão com a ajuda da explicação da professora.

Por fim, os alunos foram questionados sobre a interpretação referente à estrofe: "Que ainda resta um sonho. Uma esperança. Atrás de um sorriso de qualquer criança. Só há uma chance de sobreviver", e sobre quais atitudes 
ajudariam a diminuir a quantidade de resíduo descartado no dia a dia, e destacaram: cuidar do ambiente, jogar a sujeira dentro da lixeira, reciclar, fazer economia nas coisas que usamos para não sobrar. A aluna $C$ referiu-se ao consumismo dizendo: "- é gastar demais, à toa...", e que devemos evitar.

Compreendendo que a humanidade tem demonstrado interesse em consumir de forma desenfreada, devido à rápida expansão econômica, urbanização, mudança de estilo de vida, e outras transições sociais no mundo, demandando recursos maiores do que o planeta pode fornecer, é importante desde as séries iniciais, levar o aluno à conscientização (SILVA; OLIVEIRA, 2009).

Assim, após o término das discussões foi proposta uma atividade que individualmente os alunos deveriam elaborar uma lista, denominada "lista de consumo". Dentre os cinco itens que gostariam de adquirir, os alunos escolheriam os dois principais, e circulariam na classe com a tarefa de pensar e justificar oralmente se os outros itens eram realmente importantes. A Figura 2 traz como ilustração duas listas elaboradas por dois alunos da turma.

Figura 2 - Listas de consumo de alunos (esquerda: aluna I; direita: aluno B).
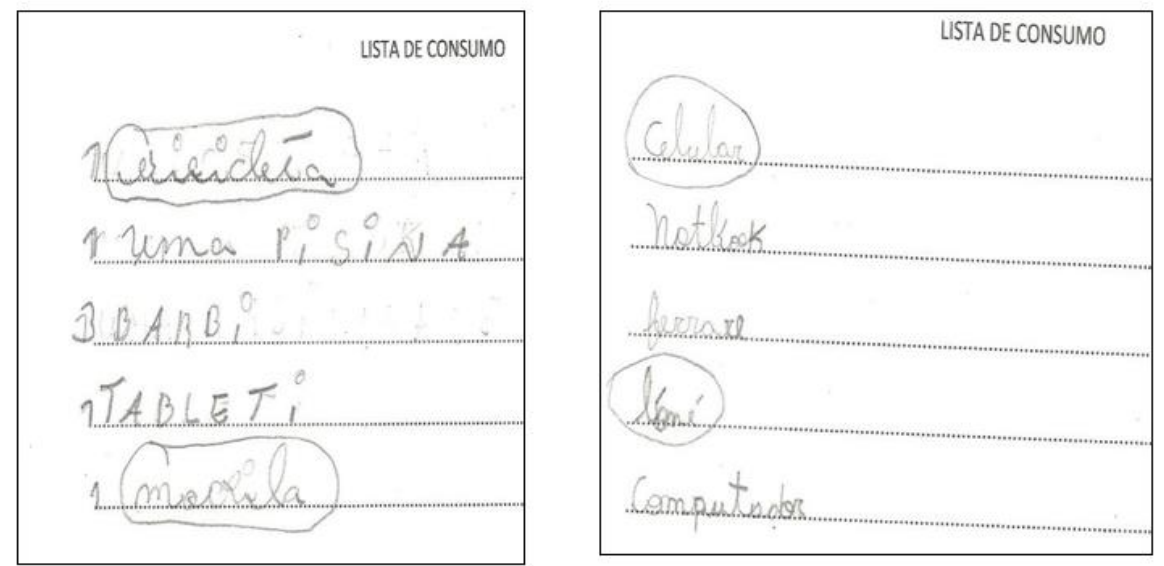

Fonte: arquivo dos autores.

A aluna I justificou a escolha por bicicleta e mochila dizendo que a bicicleta é importante para andar pelos lugares e a mochila era referente ao desenho animado favorito dela, Monster High. O aluno B justificou suas opções, celular e boné, dizendo que os outros itens poderiam exercer a mesma função do celular, logo, não precisava ter os três produtos.

A televisão, internet, rádio e outros meios de comunicação estão sempre mostrando produtos novos e atraentes, incitando a população a comprar cada vez mais. Houve um diálogo com os alunos acerca das suas respostas, levandoos a uma reflexão sobre o que realmente seria útil adquirir, com posicionamentos sobre escolhas mais conscientes, sem consumismo.

O ensino de ciências pode contribuir para instrumentalizar os alunos para ações mais responsáveis no meio social, para isso é necessário investir em educação científica desde as séries iniciais, pois é fundamental para a construção de uma sociedade democrática, economicamente produtiva, mais humana e sustentável (VIECHENESKI; CARLETTO, 2012, p.30). 


\section{Considerações Finais}

A escola como espaço privilegiado de educação científica deve ser um ambiente que promova a discussão, questionamentos e reflexão, evidenciando que o conhecimento científico é uma produção coletiva historicamente construída.

A oficina de música possibilitou uma prática docente mais dinâmica e desenvolveu nos discentes capacidades argumentativas, e a postura analítica acerca da ciência e tecnologia, contribuindo para o estímulo da alfabetização científica no primeiro segmento do Ensino Fundamental.

Os temas sociocientíficos lixo e ambiente foram explorados considerando a realidade social na qual os alunos estão inseridos, e através do compartilhamento de experiências incentivou-se o diálogo, ultrapassando a mera reprodução de conteúdos destituídos de significados e sentidos.

A partir da contextualização realizada por meio da letra da música, foi perceptível o envolvimento e participação dos alunos, a reflexão em relação às questões sociais do desenvolvimento da ciência, a articulação entre as situações de vidas e conteúdo científico proposto, o estímulo ao debate e o desenvolvimento do senso crítico.

Espera-se que a pesquisa aqui apresentada, em que se destaca a contribuição que a música pode trazer a alfabetização científica, colabore com o trabalho do professor em sala de aula. Dessa forma, o docente poderá encontrar mais uma possibilidade para o Ensino de Ciências, promovendo uma formação cidadã. 


\title{
Harmony between the practice of science teachers educational and brazilian popular music: possibilities for education STS
}

\begin{abstract}
In this work was studied as music workshops and socio-scientific topics can contribute to the scientific literacy. The qualitative study was carried out with students of the fourth year of elementary school. The socio-scientific issues were listed considering the study in the official curriculum and contextualization with the reality that exists in the school where conducted workshops, which are was: environment and waste. During the workshops, questions that could be investigated by interpreting music and where students could talk about their life experiences were developed. To stimulate discussions, we used the music "Lixo no Lixo", by Falamansa group. From the interpretation of the song's lyrics were related situations experienced by students and scientific and technological concepts. The music workshop for science education has enabled a more dynamic teaching practice and developed in students argumentative skills, contributing to the improvement to civic improvement.
\end{abstract}

KEYWORDS: Science education. Scientific literacy. Socio-scientific issues. Elementary school. Music workshops. 


\section{REFERÊNCIAS}

BARROS, M. D. M.; ARAÚJO-JORGE, T.; ZANELLA, P. G. A música pode ser uma estratégia para o ensino de ciências naturais? Analisando concepções de professores da educação básica. Ensaio - Pesquisa em Educação em Ciências, v.15, n. 01, p. 81-94. 2013.

BARROS, M.D.M.; ARAÚJO-JORGE, T., E DINIZ, P. Música no Ensino de Ciências; Análise da presença de letras de música em livros didáticos de Ciências das séries finais do ensino fundamental. European Review of Artistic Studies, v.6, n.3, p. 117. 2015.

BENETTI, I; C; GRISARD, E. ; SILVA, L. M. A percepção do professor sobre os efeitos da música no comportamento dos alunos. Estudos e Pesquisas em Psicologia, v. 14, p. 474-496, 2014.

BORTONI-RICARDO, S. M. O professor pesquisador: introdução à pesquisa qualitativa. São Paulo: Parábola, 2008.

BRANDÃO, C. R.; BORGES M. C. A pesquisa participante: um momento da educação Popular. Rev. Ed. Popular, Uberlândia, v. 6, p.51-62. janeiro 2007.

BRASIL. Lei №. 9.394, de 20 de dezembro de 1996. Lei de diretrizes e bases da educação. Ministério da Educação, Brasília, 1996.

BRASIL. Parâmetros Curriculares Nacionais: ciências naturais/ Ensino de primeira à quarta série. Secretaria de Educação Fundamental, Brasília, 1997.

DELIZOICOV, D.; LORENZETTI, L. E. Alfabetização científica no contexto das séries iniciais. Ensaio - Pesquisa em Educação em Ciências, v.3, n.1, 37-50, 2001.

FABRI F.; SILVEIRA, R. M. C. F. O ensino de ciências nos anos iniciais do ensino fundamental sob a ótica CTS: uma proposta de trabalho diante dos artefatos 
tecnológicos que norteiam o cotidiano dos alunos. Investigações em Ensino de Ciências, v. 18, p. 77-105. 2013.

FAGUNDES, E. M; PINHEIRO, N. A. M. A abordagem da Ciência, Tecnologia e Sociedade no Ensino de Ciências: a relevância da prática docente. VOOS Revista Polidisciplinar Eletrônica, Guairacá, v. 05, p. 20-34, julho 2013.

FREIRE, P. A educação e mudança. Rio de Janeiro, RJ: Paz e Terra, 2011.

LOUREIRO, A. M. A. O ensino de música na escola fundamental. $7^{\text {a }}$ ed. v. 1. Campinas: Papirus, 2010.

MEDEIROS, A. B.; MENDONÇA, M. J. S. L.; SOUSA, G. L.; OLIVEIRA, I. P. A importância da educação ambiental na escola nas séries iniciais. Revista Faculdade Montes Belos, v. 4, n. 1, set. 2011.

MINAYO, M. C. S. Pesquisa social: teoria, método e criatividade. Petrópolis, RJ: Vozes, 2012.

MOREIRA, I. C.; MASSARANI, L. (En)canto científico: temas de ciência em letras da música popular brasileira. História, Ciências, Saúde - Manguinhos, v. 13 (suplemento), p. 291-307, outubro 2006.

MOREIRA, I. C; MASSARANI, L. Música e Ciência: ambas filhas de um ser fugaz. Anais da X Reunión de la RED POP y el Taller Ciência, Comunicación y Sociedad. Costa Rica, 2007. Disponível em: <http://www.cientec.or.cr/pop/memoria/index.html>. Acesso em: 04 janeiro 2017.

MUNDIM, J. V; SANTOS W. L. P. Ensino de ciências no ensino fundamental por meio de temas sociocientíficos: análise de uma prática pedagógica com vista a superação de uma prática pedagógica com vista a superação do ensino disciplinar. Ciência \& Educação, v. 18, n. 4, p. 787-802, 2012.

NASCIMENTO, F.; FERNANDES, H. L.; MENDONÇA, V. M. O ensino de Ciências no Brasil: história, formação de professores e desafios atuais. Revista HISTEDBR Online, Campinas, n.39, p. 225-242, 9, set. 2010. Disponível em: <http://www.histedbr.fae.unicamp.br/revista/edicoes/39/index.html>. Acesso em: 04 janeiro 2017. popularização da ciência e um recurso de aprendizagem no processo 
educacional. Anais do Seminário Nacional de Educação Profissional e Tecnologia, v. 1, 2008. Brasil.

PINHEIRO, N. A. M; SILVEIRA, R. M. F.; BAZZO, W. A. Ciência, Tecnologia e Sociedade: a relevância do enfoque CTS para o contexto do Ensino Médio. Ciência e Educação, São Paulo, v. 13, p. 71-84, 2007.

RICARDO, E. C.; ZYLBERSZTAJN, A. Os Parâmetros Curriculares na Formação Inicial dos Professores das Ciências da Natureza e Matemática do Ensino Médio. Investigações em Ensino de Ciências (Online), v. 12, p. 339-355, 2007.

SANTOS, B. S. R. Utilização da música como fornecedora de conceitos subsunçores à aprendizagem de conceitos de acústica. Anais do SINECT, Ponta Grossa, Paraná, 2014. Brasil.

SANTOS, W. L.P. Educação científica na perspectiva de letramento como prática social: funções, princípios e desafios. Revista Brasileira de Educação, São Paulo, v. 12, n.36, set/dez, 2007.

SILVA, S. A. M.; OLIVEIRA, A. L. A música no ensino de ciências: perspectivas para a compreensão da ecologia e a temática CTSA (ciência, tecnologia, sociedade e ambiente). 2009. Revista Eletrônica dia a dia Educação, Curitiba, 2009.

SILVEIRA, M. P.; E KIOURANIS, N. M. M. A música e o ensino de química. Química nova na escola, n.28, p.28-31. 2008.

SOARES, M. N.; LABARCE, E. C.; BONZANINI, T. K.; CARVALHO, F. A.; NARDI, R. Perspectivas atuais da pesquisa em ensino de Biologia. Anais do VI ENPEC. Florianópolis, 2007. Brasil. Disponível em: $<w w w . n u t e s . u f r j . b r / a b r a p e c / v i e n p e c / C R 2 / p 341 . p d f>$. Acesso em: 04 janeiro 2017.

SPANAVELLO, C; BELLOCHIO, C.; Educação musical nos anos iniciais do ensino fundamental: analisando as práticas educativas de professores unidocentes. Revista da ABEM. Porto Alegre: n. 12, março, 2005.

VIECHENESKI, J. P., CARLETTO, M. R. Ensino de Ciências e Alfabetização Científica nos anos iniciais do Ensino Fundamental: um olhar sobre as escolas públicas de Carambeí. Anais do VIII ENPEC e I CIEC - Congreso Iberoamericano de Investigación en Enseñanza de las Ciências, Campinas, SP. 2011. p. 23-34. Brasil. 
DOI: 10.3895/rbect.v10n1.5721

Como citar: DIAS, G. S.; MESSEDER, J. C. Harmonia entre a prática pedagógica de professores de ciências e a música popular brasileira: possibilidades para um ensino CTS. Revista Brasileira de Ensino de Ciência e Tecnologia, v. 10, n. 1, 2017. Disponível em:

<https://revistas.utfpr.edu.br/rbect/article/view/5721>. Acesso em: xxx.

Direito autoral: Este artigo está licenciado sob os termos da Licença Creative Commons-Atribuição 4.0 Internacional.

(c) (1)

Página | 95

R. bras. Ens. Ci. Tecnol., Ponta Grossa, v. 10, n. 1, p. 1-15, jan./abr. 2017. 